\title{
Innovative Curriculum to Enhance the Learning Experience of Electrical and Mechanical Engineering Students
}

\author{
http://dx.doi.org/10.3991/ijep.v6i3.5765
}

\author{
M. Fikret Ercan, Dennis Sale and Noel Kristian \\ Singapore Polytechnic, Singapore
}

\begin{abstract}
This paper presents an integrated engineering enrichment program for the electrical and mechanical engineering students at polytechnic level. This program promotes design thinking and problem based learning and it is spread into three years of engineering education. The entire program is founded upon design-and-build type of projects where students get to practice engineering design process with increasing complexity in each semester. It is implemented in a studio environment equipped with necessary technical tools such as prototyping machines, 3D printers, soldering stations and so on. At the beginning, forty students enrolled to the program; it is now expanded to accommodate eighty students. A detailed description of the program and its structure are presented together with our evaluation of results and observations.
\end{abstract}

Index Terms-Curriculum design, engineering education, integrated curriculum, student motivation.

\section{INTRODUCTION}

In our institution, Singapore Polytechnic, an initiative for rethinking engineering education using the ConceiveDesign-Implement-Operate (CDIO) Engineering Education Framework has been implemented in the last decade in order to prepare our students for the challenges they will face in the modern industrial context. The initiative represented a response by engineers in industry, government and academia to a concern about the present state of engineering education. Essentially, engineering education was seen as over prioritizing the teaching of theory, especially mathematics and science, while not paying enough attention to the real world of engineering practice and the need for skills such as design, teamwork and communications [1]. It is therefore important to reframe key aspects of curriculum, teaching and assessment practices to meet not only the technical competencies required of our students but also some important attributes and skills needed in work life. The polytechnic implemented CDIO from 2006 and completed a comprehensive review of the implementation process [2]. This proved to be positive in terms of offering a more exciting and real world approach to teaching engineering.

Since the embedding of CDIO, we have been particularly keen to experiment with the development of certain key attributes for engineering graduates today, especially the capability for creative design involving the solving of engineering problems from the perspective of various fields of study, other than the one specialized in. This requires the systematic integration of different perspectives and skills in the curriculum program to enable our engineering students to develop the capability for making connections and being able to transfer learning across various disciplines so that the context of engineering problem-solving becomes more sophisticated and multidisciplinary.

The institution, being a polytechnic, primarily responds to the needs of local industry which is seeking engineers with hands on skills who can fit into the work force rapidly. Hence, by introducing our students to the design process, by getting them involved in problem solving through real work projects, using prototyping tools and devices, their learning is made more active and experiential from the very beginning of their study. A key aim is to facilitate an understanding of the thinking processes of engineers, and making that thinking visible to students, so that they can model what engineers do in solving engineering problems. This is further reinforced through collaborative hands on activities in an integrated curriculum structure that builds the acquisition of personal and interpersonal skills (e.g., decision making, self-directed learning, teamwork and communication), across a variety of disciplines, linking theory and practice. [3]. To specifically enhance the "conceive" and "design" aspects of CDIO, the methodology of Design Thinking [4] was adopted to enable students to develop stakeholder empathy, research skills, and creative thinking. Finally in terms of the pedagogic context, we are concerned with the holistic development of an individual together with his/her engineering skills. Underpinning this curriculum redesign is a strong emphasis on robust curriculum alignment, whereby the range of learning activities, and subsequent assessment methods are specifically focused on facilitating the desired learning outcomes [5].

With fast prototyping and manufacturing tools, such as 3D printing, becoming available, the future of engineering and manufacturing is highly dynamic and innovative. It is widely accepted that nowadays innovation is the key differentiator in various industries [4] [6]. The job scope of engineers therefore is not limited to delivering products that meet defined specifications or making incremental improvements on them, but also to develop innovative products and services. Consequently, it is important to inculcate a culture of innovation and making in our students. Considering the needs of modern engineering graduates in Singapore, our institution adopted and implemented CDIO and has adapted the 'design thinking' approach more recently for conceiving user-centered innovative products and services [7]. The objective of adopting design thinking was more than making students more creative and innovative, but also developing skills at- 
tributed with good designers, such as dealing with uncertainty, working in teams, making decisions, and seeing the bigger picture.

To further extend the broad curriculum objectives of CDIO and further refine our focus on developing a more interdisciplinary approach, we introduced an enrichment program for electrical and mechanical engineering students. This was extensively focused on integrated 'handson' project based activities to broaden students understanding of engineering concepts across various disciplines. Design Thinking was fully employed in a studio based teaching environment rather than lecture theatres and classrooms. This encouraged an active and collaborate learning environment throughout the learning activities. In the literature this approach is commonly referred to as 'studio-based pedagogy' and is being applied in many disciplines [8].

In the remainder of this paper, we will present the enrichment program and the individual modules taught (The term "module" refers to "course" as it is commonly used term in our institution). An evaluation of the program to date is presented.

\section{AN OVERVIEW Of THE Program}

Mechanical and Electrical engineering students are the largest cohort in our institution where the total cohort is about eight hundred students. Due to large student cohort and limited resources, the enrichment program described here is offered to a limited number of students. It is available as an option to the students of these two streams, and is announced during the first semester of their freshman year. The enrichment program starts in the second semester. In order to develop an understanding of the program and what is expected of them, applicants are put through an orientation camp before the program commences. At the end of this camp, selected students are accepted into the program. Through this orientation camp, faculty observe the attitude of the applicants toward project-based learning program since the program is suitable for students that are intrinsically motivated and not driven solely by external factors (e.g. obtaining high grades) In the following semesters, students take three integrated project modules, followed with an optional overseas attachment and mandatory capstone project. Figure 1 shows an overview of the 3-year program.

\section{A. Nature Inspired Design Module}

Nature inspired design is an integrated hands-on module for students to put engineering theory into practice by working in teams. This module is delivered as a whole day work shop once a week. In this program, students design and build engineering artefacts taking inspiration from nature. For this particular module, we hope that students have fun and cultivate an interest in engineering. On the 'hind-side', one of our primary objectives is to inculcate observation skills in our students. The teaching team comprises faculty members from three schools namely design, electrical engineering and mechanical engineering. At the beginning of this module, student teams are formed with a mix of members from two different disciplines.

During the fifteen week period students are introduced to various topics as well as necessary practical skills from all these three disciplines. These topics are: CAD design, mechanism and mechanical components, manufacturing

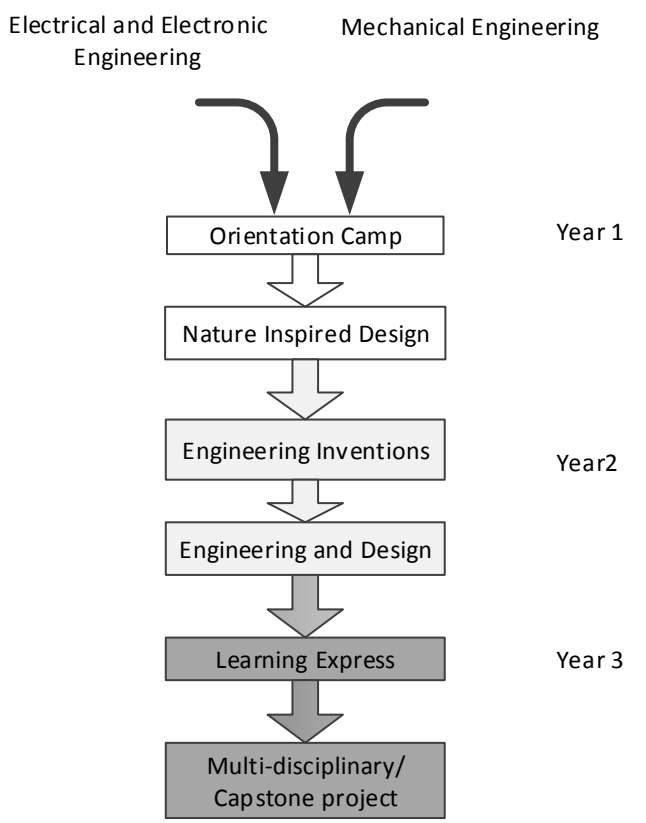

Figure 1. An over view of the enrichment program.

process (mechanical engineering), basic electronics and circuits, Arduino programming (electrical engineering), design thinking, design process and principles, design presentation (design). They are carefully selected so that essential practical skills and the knowledge that benefits the implementation of their project can be conveyed. Among these three main areas, more emphasis is given to the design component since we would like to embed design thinking skills to our students. This will benefit them in subsequent project based modules.

A suitable theme is instrumental in integrating the various disciplines. Nature inspired design module is built upon bio mimicry that is concerned with deriving solutions to problems inspired from nature. We try to integrate mechanical engineering, electrical engineering and design topics under this theme. Each semester, application area is altered such as "animats", "indoors and living", "entertainment" and so on. This gives students a more focused view in terms of application of their project ideas. The challenge given to the students is two-fold. At the first stage students observe nature, select an animal or creature that they are interested in and analyze one of its features thoroughly, such as its motion, behavior, growth, or survival capability. In the second stage, they design an engineering artefact which is inspired from this study and demonstrate its potential application. This produced many different and interesting projects every semester, hence encouraging a great deal of creativity. For instance, in one of the project students were inspired by caterpillar locomotion. They study caterpillar motion and deliberate its potential applications as a robot cleaner, conveyor belt or water pump. Ideation stage of the project relies on topics learned during design sessions. The implementation of the mechanical structure is done by using cams, gears and other mechanical components. The actuation is provided by motors, batteries and basic circuitry. Overall project development requires an integration of various engineering principles that students have learned. In summary, students demonstrate abundant creativity and resourcefulness in developing their projects. Some of the interesting project ideas are shown in [9] [10]. 
PAPER

INNOVATIVE CURRICULUM TO ENHANCE THE LEARNING EXPERIENCE OF ELECTRICAL AND MECHANICAL ENGINEER...

\section{B. Engineering Inventions Module}

Engineering inventions is an integrated module for students to establish the link between math, science and different disciplines of engineering. Students design and build engineering artifacts by taking inspirations from the history of Asian engineering and inventions. In addition to our broader pedagogical objectives, we also hope to inculcate research skills in our students as well as widen their horizons through historical analysis. Furthermore, students are expected to do in depth analysis and understand the impact of these inventions from various perspectives beyond an 'engineers' framing. This is strongly reinforced through the program as what might constitute a good solution from an engineering point of view, may not be similarly perceived by all users. For example, while a mechanical appliance for handicapped persons might work well from a technical point of view, it may not be used by individuals' who perceives it as ugly and experience feelings of negative self-consciousness. The importance of being able to think both critically and across different fields is both essential and challenging for engineering graduates, though rarely explicitly taught [11].

It was important to ensure that students were aware of the importance of good thinking as part of their overall learning purpose and strategy. Hence, we made every effort to integrate types of thinking (e.g., critical and creative) into the project activities and make them explicit visible - in practice [12] [13].

A teaching team of four faculty members deliver this course. Two permanent members of the course are from electrical engineering and mechanical engineering. In addition, two other faculty members from math and science and chemical and life sciences are involved as guest lecturers. At the beginning of this module, student teams are reshuffled so that students learn to work with different teams as it is the case for real work environments.

During the fifteen week period students are introduced to various topics from all the four disciplines, each showing the link between ancient to modern application of various engineering components and principles. Briefly, these topics are: Function and mechanism analysis (mechanical engineering), sensors and actuators (electrical engineering), biomass energy, biofuel production, heat and mass transfer in biofuel production (chemical and life sciences), vector analysis, correlation, causality and regression (math).

The project topic focuses solely on past engineering inventions from Asia. Students study works of ancient Asian engineers and deliver a project plan. Project deliverables can be varied, for example a working prototype, a smallscale implementation for demonstration, a modern adaptation of the invention, or a computer simulation study. Some groups chose to make a working model of the invention such as a Chinese repeating cross bow, double piston air bellow, and chain pump. On the other hand, some chose to build a working model of the invention such as Cresco graph, Chinese water clock and Chinese seismometer but modernized it with electronic circuits, LCD displays and microcontrollers. More details on this course and some of the interesting student projects can be found in [14].

\section{Engineering and Design Module}

This module introduces design principles and application of engineering theory into practice. Students design and build engineering artefacts taking inspiration from current issues. The project theme in this module is flexible and changes regularly; the current project theme is 'water', since this is a systemic problem scenario in the Singapore context. The Engineering and Design module is the last structured project module. As students have now gained more experience and developed their engineering skills, it is considered most appropriate to introduce them to solving more authentic and realistic engineering problems. This will extend their proficiency in developing essential thinking skills, especially generating possibilities, which is key to creative thinking.

The module content introduces the necessary knowledge that may be beneficial in project development such as elementary fluid dynamics, flow in close conduits, water proofing techniques (mechanical engineering), Hydroelectricity, data acquisition (electrical engineering), water chemistry, water purification, water management (chemical and life sciences), applied differential equations and numerical methods (math).

The project theme naturally enhances students' awareness of current issues about their environment and ponders upon engineering solutions. As the project theme is "water', students are expected to develop projects that exploit properties of water or addresses issues related to water (e.g., water quality, filtering, and sanitation to demonstration projects that exploits the properties of water such as buoyancy, pressure, cooling). Students are introduced to this challenge from the beginning of the semester and are expected to deliver a working prototype at the end of the program. Examples of some interesting project ideas from students include a portable water quality measuring device, an amphibian robot and a swimming robot that performs snake like motions and it is designed for cleaning oil spills. With the swaying motion the robot sweeps a large area and increases the chances of capturing oil particles with the cotton based filters attached to its tail. A detailed description of this course can be found in [15].

\section{Assessment Methods and Tools}

There are two major components to the assessment: individual and teamwork. There are two formative assessment components during the term and a summative component at the end of the project. There are four main areas that students are assessed in: research process and journal; communication and teamwork; assignments; and final project work. Individual contributions to the team are assessed via research process and research journal as well as assignments. During the presentations and final project work, we try to observe aspects of student's teamwork activity and assess individuals' contributions.

\section{E. Learning Express: Real Problem-solving in an International Context}

The final component of the enrichment program is a structured learning experience whereby students work on an overseas project, which we refer to as "Learning Express". The objective of Learning Express is to create opportunities for students in using their technical skills and knowledge to tackle social and environmental issues outside their immediate world, typically outside of Singa- 
pore. It also provides a particularly impactful experiential learning experience in which our students need to display the ability to work both in an interdisciplinary and different cultural context. The program has two main components: learning express 1 (LeX1) and learning express 2 (LeX2) that take place consecutively. In LeX1, students undergo a two weeks expedition in selected villages in South East Asian countries (e.g., Indonesia, Vietnam and Thailand) where they immerse themselves into the lives of the community and seek to understand their needs in order to develop possible solutions.

The main objective of LeX1 is to create a learning experience for student's that involves them living in a foreign context, building empathy and collaboration with the local community, and working with them on solving 'felt' problems. In LeX2, students build working prototypes based on the concepts they have conceived in LeX1. They are assigned to faculty who has relevant expertise to their project, which is similar to a capstone project-albeit with shorter duration. At the final week, students return to the village and implement the solution which involves transferring their know-how on building, operating and maintaining that solution.

Learning express program is conducted in collaboration with a local institution at the host country. The program is announced through personal and institutional communication and networking means. A memorandum of understanding is signed with the institutions who are interested in to participate. Based on the agreement, the host institution provides equal number of students to team up with our students in the design challenge. A short course on design thinking is also provided to instructors and teachers of the host institution so that they can prepare their students. Host institute is also instrumental in finding the right local community to conduct a meaningful project. The program is financed for our students through student development fund of our institution.

Figure 2 shows an example project which is developed to help the laborious and tedious process of converting cassava roots into crackers in Kradenan village in Yogyakarta. Students identified the most unpleasant process for the workers as the squeezing of the cassava to obtain the unfermented cassava juice. While the process itself is tedious and consumes lots of energy, the workers still enjoy doing this job due to the presence of the other coworker doing the same thing. With these insights, students created a manually operated squeezer for two people to help the workers reduce the strength needed in this process. This final concept was well received by the community. The example project described here undertake by eight students. The conceiving and ideation process took one week during their stay in the village. The further improvements and development of a final product took one year.

\section{Program Evaluation}

In order to obtain useful, feedback sessions were held with students at the end of each semester over the duration of the program. This involved the use of questionnaires (e.g., fixed rating scale and open response items) and a focus group interview with a sample of students. Questionnaires focused on how each module influenced selected areas of student learning and key competencies such as autonomy, creativity, integration, hands on skills, team

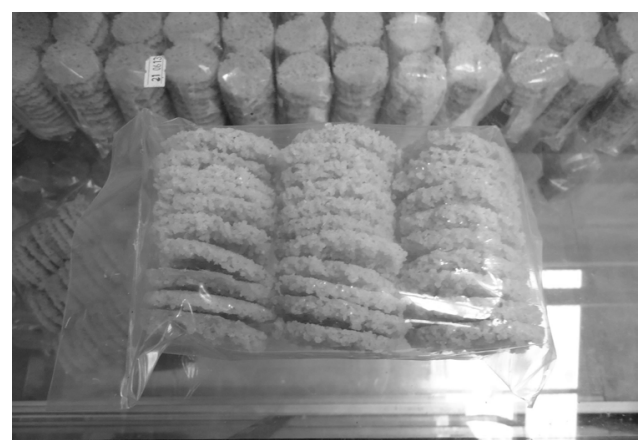

(a)

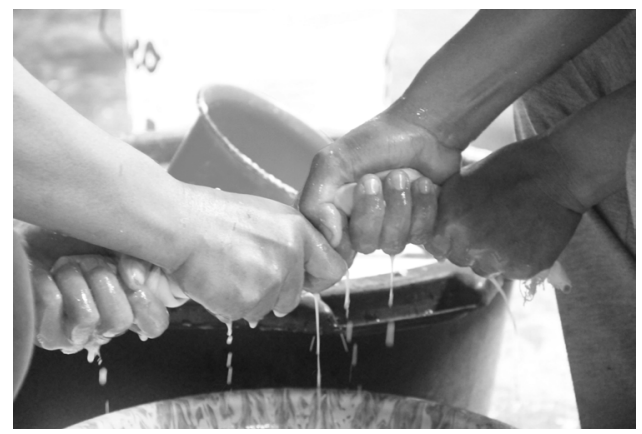

(b)

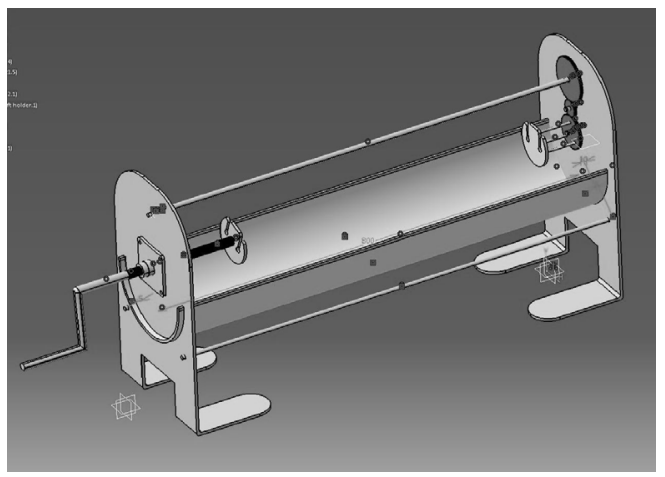

(c)

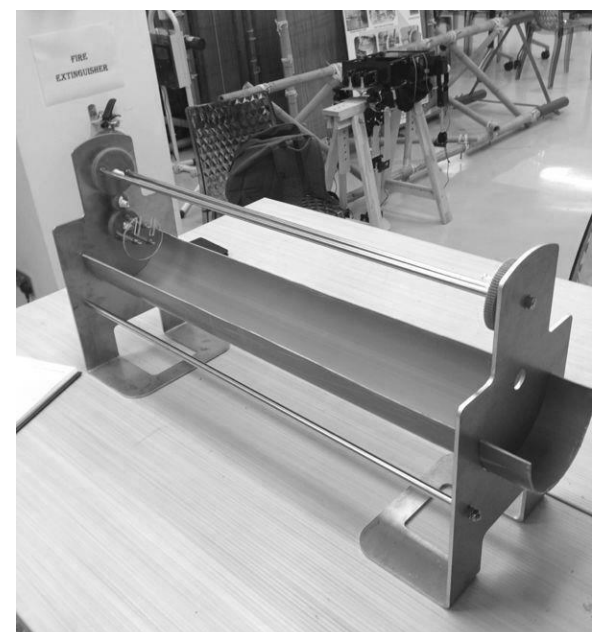

(d)

Figure 2. (a) Cassava crackers sold in local market. (b) Manual cassava juice extracting method; two workers squeeze the juice by twisting the sack filled with shredded cassava in opposite directions (c) CAD design of envisioned device where same motion is done by rotating the handles on both sides in opposite directions generating squeeze motion. Handle and gear mechanism makes the job less strenuous (d) Final product implemented with aluminum and stainless steel material. The finished product delivered to village and well received by the users. 
PAPER

INNOVATIVE CURRICULUM TO ENHANCE THE LEARNING EXPERIENCE OF ELECTRICAL AND MECHANICAL ENGINEER...

work and communication. From the responses to the three structured project modules, over three semesters, and the final LeX module, we attempted to ascertain student's progress in terms of knowledge acquisition and application of these key attributes. Table 1 illustrates the questionnaire structure used after the first project module, Nature Inspired Design, which contains a number of statements relating to different aspects of learning from the module. Students respond by selecting the rating from the 5-point scale that best reflects their experience (where 5 represent very much the case and 1 represents not at all the case for the student).Average ratings for each question is also listed in Table 1.

Figure 3 shows students response to the questionnaire. We noted that $69.22 \%$ agreed (15.38\% strongly agreed) that the module has increased their confidence in learning independently. A similar pattern is observed in their response to the question if the module enabled them to see the links between diverse fields in engineering applications. From the response, we infer that about $73.07 \%$ agreed $(23.07 \%$ strongly agreed) that one of the key objectives, integration, has benefited their learning. Only a minority of $3.84 \%$ disagreed. In response to the modules' influence on developing skills in using various types of tools and equipment for prototyping, fabrication and implementation of project ideas, an overwhelming $84.3 \%$ (23.07\% strongly agreed) agreed. In response to questions on communication skills, a majority of $73.07 \%(15.38 \%$ strongly agreed) agreed that the module helped them communicate ideas more effectively. However, student responses to questions on team work shows that relatively less, $46.09 \%$ (7.69\% strongly agreed) felt their confidence in team work and ability to meet the objectives of the team had benefited. $15.38 \%$ disagreed $(7.69 \%$ strongly disagreed). Results show that among all our objectives, enhancing student's ability in teamwork was not as effective compared to the other attributes. From written comments, we see that the majority of the students commented that they are more independent in their learning and comfortable to take up new projects.

They also commented that they benefited significantly from learning prototyping and fabrication tools. On the other hand, they found that module content and the workload was heavy and the time given is not sufficient. In summary, further improvements on the module to address these issues are needed - basically a better time management schedule and some refinement on methods to improve teamwork skills.

A similar feedback session was employed for the Engineering Inventions module. Table 2 shows the questionnaire used and the average rating for each question. Although the statements in the questionnaire are framed differently, we still focused primarily on the core competency areas identified prior. Figure 4 shows students responses to the questionnaire. From the response, we found that $64 \%$ agreed (12\% strongly agreed) that the teaching approach supported autonomy. There was $0 \%$ disagreement in this area. For the question relating to integration, 64\% of the students agreed (12\% strongly agreed) that the integrated approach provided a better understanding of engineering. A minority $8 \%$ disagreed. When we compare these results with the previous module, students' response to "autonomy" and "integration" did not vary significantly. In fact, the average ratings for questions on autonomy and integration were increased compared to Nature In- spired Design module. When we examine the ratings on practical skills and a culture of making, we observe a significant improvement. For instance, $84 \%$ agreed (32\% strongly agreed) that they are now more fluent in using tools for prototyping/fabricating engineering projects. Our major concern was on team work and communication skills. Our classroom observations during the delivery of the module were positive and this is supported with students' response to the questionnaire as well. This time $64 \%$ (24\% strongly agreed) agreed that they can work effectively with different personalities when doing teambased projects. A minority $4 \%$ disagreed. From Table 2, we can see that the average rating in this area has improved from 3.3 previously to 3.8 . As mentioned earlier, student teams for each module project is determined randomly at the beginning of the semester. Consequently, team members were different for this module as compared to previous semester. However, we also connect this improvement to closer monitoring of group dynamics by lecturers conducting the module as well as students increasing maturity over time.

The last structured project module was Engineering Design. Table 3 shows the questionnaire used at the end of the semester and the average rating for each question. This module evaluation was more focused on students understanding of engineering principles, tools and methods in solving real engineering problems. Furthermore, we are interested in students' confidence in their ability to use engineering skills for tackling these problems. Figure 5 shows students response in detail. From the response, we found that $75 \%$ agreed (25\% strongly agreed) that they feel confident to come up with useful and novel solutions when confronted with an engineering problem. Approximately $70 \%$ agreed that the module enabled applying engineering principles to engineering problems. However, the student evaluation also indicated that this module remained somewhat isolated in its content. At least, it was not obvious to the students that its content was linked to the knowledge build up in previous project modules (Disagreement in Q2 is $16.6 \%$ and Q7 20.7\%). Therefore, further improvement in module design and delivery may be necessary.

A significant part of the evaluation involved a focus group interview with 10 students who have completed all the key program components. The use of focus groups was employed for the following main reasons:

- Enables the collection of data relatively quickly from a larger number (as compared to individual interviews) of research participants

- Provides a more naturalistic context than the individual interview in that it is closer to the everyday conversations that people typically participate in

- Offers the potential of a synergistic effect in that it allows participants to react to and build upon the responses of other group members, producing richer accounts of the experience being investigated.

Post the focus group interview, subsequent collaboration with students was sought to verify the inference and interpretations of the student experience made by the evaluator who was not a member of the faculty teaching team. This was to reduce the impact of recording errors and ensure more valid interpretations based on the data, akin to a grounded theory perspective in qualitative research [16]. 
The focus group verified much of the findings from the previous evaluations. The challenging integration effort was seen as a very positive feature of the program, both in terms of technical integration (e.g., within the engineering field and across the engineering disciplines involved) as well as with the other generic competencies (e.g., teamwork, communication).

Of keen interest for us was the almost unanimous agreement on the educational value of the (Learning Express) in terms of:

- Enhancing empathy and understanding of how people experience the world, and relate to it, from different cultural contexts

- Applying concepts and skills (both technical knowledge and generic competencies - critical and creative thinking, teamwork and communication) to more authentic engineering problem-solving

- Reframing of own situated position of relative privilege in world context

Students reported a significant heightened sense of work effect to meet the learning outcomes and project deliverables.

\section{CONCLUSIONS}

This paper has summarized our initiative to extend our implementation of the CDIO engineering education framework through an enrichment course that sought to maximize certain key features such as interdisciplinary, collaborative active and experiential learning, and authentic assessment for learning. We observed that engineering as well as communication and teamwork skills of students participate in this program developed significantly. When compared to their peers, they demonstrate a higher level confidence and eagerness to take on new challenges. The final learning experience, 'Learning Express', provided the added challenge for students who had to apply a range of technical and generic skills (e.g., critical and creative

TABLE I.

QUESTIONNAIRE USED FOR NATURE INSPIRED DESIGN MODULE

\begin{tabular}{|c|c|c|}
\hline Attributes & Questions & Avg \\
\hline \multirow{2}{*}{ Autonomy } & $\begin{array}{l}\text { 1. The module has helped me to manage my own } \\
\text { learning better? }\end{array}$ & 3.61 \\
\hline & $\begin{array}{l}\text { 2. The module has increased my confidence in } \\
\text { learning independently? }\end{array}$ & 3.76 \\
\hline \multirow{2}{*}{ Integration } & $\begin{array}{l}\text { 3. The module has enabled me to see how different } \\
\text { topics are naturally connected in the real world? }\end{array}$ & 3.92 \\
\hline & $\begin{array}{l}\text { 4. I have developed a better understanding of } \\
\text { engineering? }\end{array}$ & 3.88 \\
\hline \multirow{3}{*}{$\begin{array}{l}\text { Maker } \\
\text { culture }\end{array}$} & $\begin{array}{l}\text { 5. I am able to use various types of tools for } \\
\text { prototyping/ fabricating engineering projects? }\end{array}$ & 4.07 \\
\hline & $\begin{array}{l}\text { 6. The module has developed my ability to think } \\
\text { creatively? }\end{array}$ & 3.92 \\
\hline & $\begin{array}{l}\text { 7. I feel more motivated to take on new projects } \\
\text { ideas? }\end{array}$ & 3.73 \\
\hline \multirow{4}{*}{$\begin{array}{l}\text { Team- } \\
\text { work/comm } \\
\text { unication }\end{array}$} & $\begin{array}{l}\text { 8. I am able to communicate my ideas more effec- } \\
\text { tively? }\end{array}$ & 3.80 \\
\hline & $\begin{array}{l}\text { 9. The various assignments have improved my } \\
\text { ability to use technical language when presenting? }\end{array}$ & 3.50 \\
\hline & $\begin{array}{l}\text { 10. I am better able to work effectively with differ- } \\
\text { ent personalities when doing team-based projects? }\end{array}$ & 3.30 \\
\hline & $\begin{array}{l}\text { 11. I feel more confident in helping the team to } \\
\text { meet its objectives? }\end{array}$ & 3.38 \\
\hline
\end{tabular}

thinking, communication and teamwork) in a different cultural context. Proving such enrichment programs, while offering students a more authentic and meaningful experience than much of traditional lecture based teaching poses challenges for us in choosing interesting and relevant themes, or project concepts, where integration can naturally be part of the learning experience. Organizing an integrated curriculum where faculties from various disciplines collaborate is also a challenging task. However, based on the feedback to date, there are good indications that such curriculum arrangements offer students both a more interesting learning experience as well as develop more affective aspects relating to the development of social awareness and being able to manage one's own learning.

With thoughtful translation to local contexts, similar programs can be a very effective and meaningful learning experience for students in other institutions. This is especially the case where there is a need for significant curriculum innovation to meet the demands of the modern engineering workplace.

TABLE II.

QUESTIONNAIRE USED FOR ENGINEERING INVENTIONS MODULE

\begin{tabular}{|c|c|c|}
\hline Attributes & Questions & Avg \\
\hline \multirow{2}{*}{ Autonomy } & $\begin{array}{l}\text { 1. The teaching/learning approach has provided } \\
\text { choice on how I learn the subject content? }\end{array}$ & 3.68 \\
\hline & 2. I am now able to learn more independently? & 3.76 \\
\hline \multirow{2}{*}{ Integration } & $\begin{array}{l}\text { 3. The integrated approach has helped my under- } \\
\text { standing of engineering? }\end{array}$ & 3.72 \\
\hline & $\begin{array}{l}\text { 4. I can take multiple perspectives when solving } \\
\text { problems? }\end{array}$ & 4.00 \\
\hline \multirow{4}{*}{$\begin{array}{l}\text { Maker } \\
\text { culture }\end{array}$} & $\begin{array}{l}\text { 5. I am able to use various types of tools for proto- } \\
\text { typing/fabricating engineering projects? }\end{array}$ & 4.16 \\
\hline & $\begin{array}{l}\text { 6. The module has developed my ability to think } \\
\text { creatively? }\end{array}$ & 3.96 \\
\hline & 7. I now take on new project ideas? & 4.08 \\
\hline & 8. I have acquired useful practical skills? & 3.96 \\
\hline \multirow{4}{*}{$\begin{array}{c}\text { Team- } \\
\text { work/comm } \\
\text { unication }\end{array}$} & 9. I am now better at making oral presentations? & 3.76 \\
\hline & 10. I am now better at written communication? & 3.56 \\
\hline & $\begin{array}{l}\text { 11. I am better able to work effectively with differ- } \\
\text { ent personalities when doing team-based projects? }\end{array}$ & 3.84 \\
\hline & $\begin{array}{l}\text { 12. I am better able to manage myself as an effec- } \\
\text { tive team member? }\end{array}$ & 3.92 \\
\hline
\end{tabular}

TABLE III.

QUESTIONNAIRE USED FOR ENGINEERING DESIGN MODULE

\begin{tabular}{|l|c|}
\hline \multicolumn{1}{|c|}{ Questions } & Avg \\
\hline $\begin{array}{l}\text { 1. This module has enabled me to gain a deep understanding of } \\
\text { engineering principles? }\end{array}$ & 3.79 \\
\hline $\begin{array}{l}\text { 2. I can clearly see the connections between this module and the } \\
\text { other modules in the course? }\end{array}$ & 3.54 \\
\hline $\begin{array}{l}\text { 3. I am able to come up with useful and novel solutions when } \\
\text { confronted with an engineering problem? }\end{array}$ & 4.00 \\
\hline $\begin{array}{l}\text { 4. I am able to produce a design/prototype for engineering solu- } \\
\text { tions? }\end{array}$ & 4.00 \\
\hline $\begin{array}{l}\text { 5. I am able to implement an engineering solution in a real world } \\
\text { application context? }\end{array}$ & 3.92 \\
\hline $\begin{array}{l}\text { 6. I am able to operate an engineering solution in a real world } \\
\text { application context? }\end{array}$ & 3.83 \\
\hline $\begin{array}{l}\text { 7. I feel this module has successfully built upon what I learned in } \\
\text { the previous modules? }\end{array}$ & 3.42 \\
\hline 8. I have enjoyed the learning experience in this module? & 3.67 \\
\hline $\begin{array}{l}\text { 9. This module has enabled me to apply engineering principles to } \\
\text { solving real world engineering problems }\end{array}$ & 3.75 \\
\hline
\end{tabular}




\section{ACKNOWLEDGMENT}

The authors are grateful to colleagues Jolyon Caplin, Roy Ang Chong Wei, James Lee, Wee Eng Soon, David Tan Soo Ling, Soh Ying Ying, Rubaina Khan and Tune Chien Jung in implementation of this program.

\section{REFERENCES}

[1] E. Crawley E., J. Malmqvist, S. Ostlund, D Brodeur, Rethinking Engineering Education, Springer: New York, 2007.

[2] D. Sale, The Challenge of Reframing Engineering Education, Springer: London, 2014. http://dx.doi.org/10.1007/978-981-4560$\underline{29-0}$

[3] J. Bordogna, E. Fromm and E.W. Ernst, "Engineering education: Innovation through integration", Journal of Engineering Education, Vol. 82, 3-8, 1993. http://dx.doi.org/10.1002/j.21689830.1993.tb00065.x

[4] T. Brown, Change by Design, HarperCollins: New York, 2009.

[5] J. Biggs, Teaching for Quality Learning at University - What the Student Does, 2nd Edition SRHE / Open University Press, Buckingham, 2003.

[6] V. Kumar, "A process for practicing design innovation," Journal of Business Strategy, Vol. 30, 91-100, 2009. http://dx.doi.org/10.1108/ $\underline{02756660910942517}$

[7] K. F. Soh, "An Observational Study of Infusing Design Thinking into the CDIO framework", Proceedings of 7th International CDIO Conference, 2011.

[8] P. Little and M. Cardenas, "Use of "studio" methods in the introductory engineering design curriculum", Journal of Engineering Education, Vol. 90, 309-318, 2001. http://dx.doi.org/10.1002/j.2 168-9830.2001.tb00610.x

[9] M. F. Ercan M. F. "Integration in engineering education: An experimentation of curriculum design," IEEE International Con- ference on Teaching, Assessment and Learning for Engineering (TALE), 95-97, 2012.

[10] M. F. Ercan, "Nature inspired design: An integrated approach to introduction to engineering," International Symposium on Advances in Technology Education (ISATE), 2013.

[11] T. Wagner, The Global Achievement Gap, Basic Books: London, 2010.

[12] S.D. Sheppar, K. Macatangay, A. Colby and W. M. Sullivan, Educating Engineers: Designing for the Future of the Field, San Francisco: Jossey-Bass, 2009.

[13] R. Ritchhart, M. Church, and K. Morrison, Making Thinking Visible: How to Promote Engagement, Understanding, and Independence for All Learners, Jossey-Bass: San Francisco, 2011.

[14] M. F. Ercan and S. L Tan, "Engineering inventions: Design of a project based integrated course," International Symposium on $A d$ vances in Technology Education (ISATE), 24-26, 2014.

[15] R. Khan, M.F. Ercan, N. Kristian, Y.Y. Soh and C. J. Tune, "Engineering and design: An integrated course with real world projects," CDIO 2015, Chengdu, China, 2015.

[16] A. Strauss and J. Corbin, Basics of Qualitative Research. Sage: London, 1990.

\section{AUTHORS}

M. Fikret Ercan is a Senior Lecturer in Singapore Polytechnic, School of Electrical and Electronic Engineering (mfercan@sp.edu.sg).

Dennis Sale is Senior Education Advisor at Singapore Polytechnic (dennis_sale@sp.edu.sg).

Noel Kristian is a Lecturer in chemical engineering at the School of Chemical and Life Sciences, Singapore Polytechnic (noel_kristian@sp.edu.sg).

Submitted, 12 April 2016. Published as resubmitted by the authors on 02 June 2016

\section{NID evaluation}

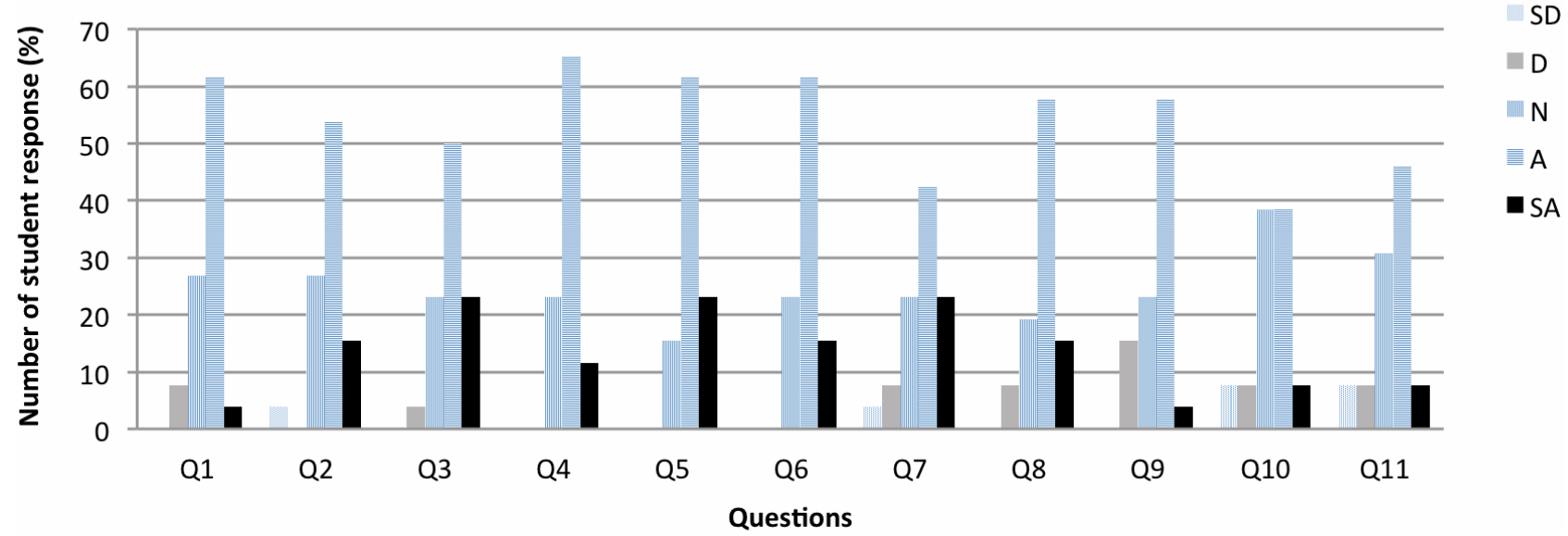

Figure 3. Students' response to the questioner on Nature Inspired Design (NID) module. (SD: Strongly disagree, D: Disagree, N: Neither agree nor disagree, A: Agree, SA: Strongly agree). 
PAPER

INNOVATIVE CURRICULUM TO ENHANCE THE LEARNING EXPERIENCE OF ELECTRICAL AND MECHANICAL ENGINEER...

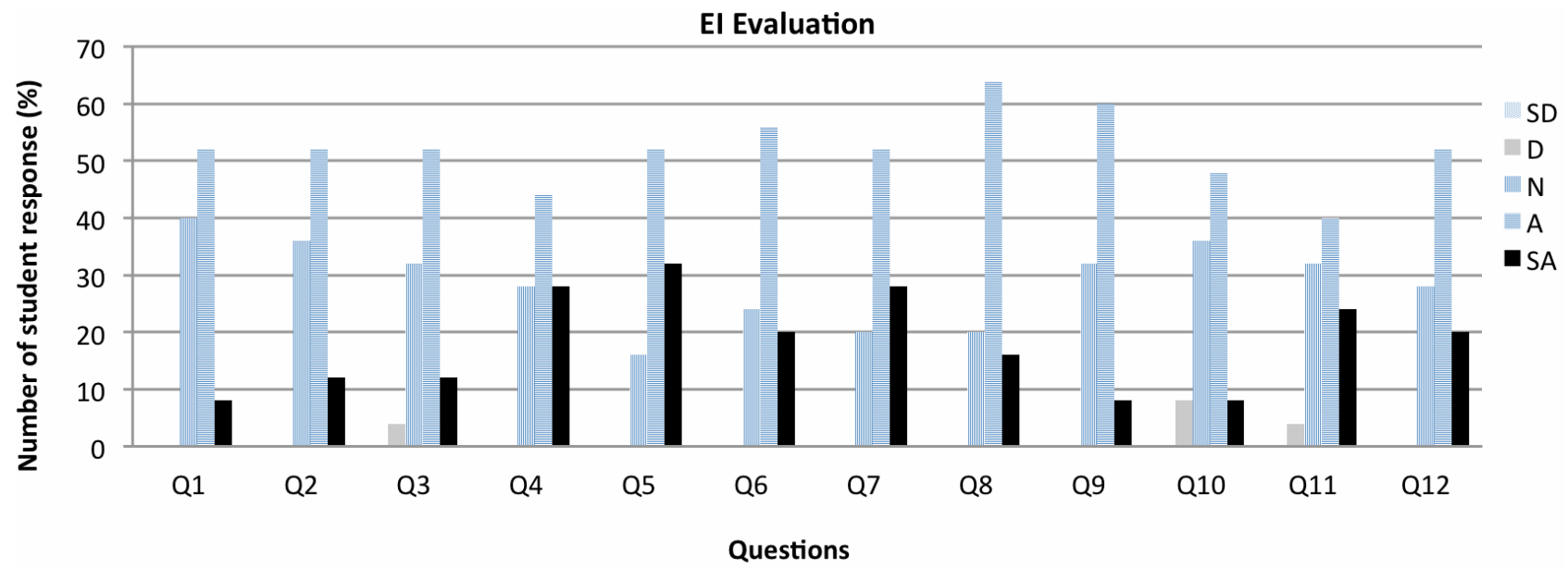

Figure 4. Students' response to the questioner on Engineering Inventions (EI) module. (SD: Strongly disagree, D: Disagree, N: Neither agree nor disagree, A: Agree, SA: Strongly agree).

\section{ED Evaluation}

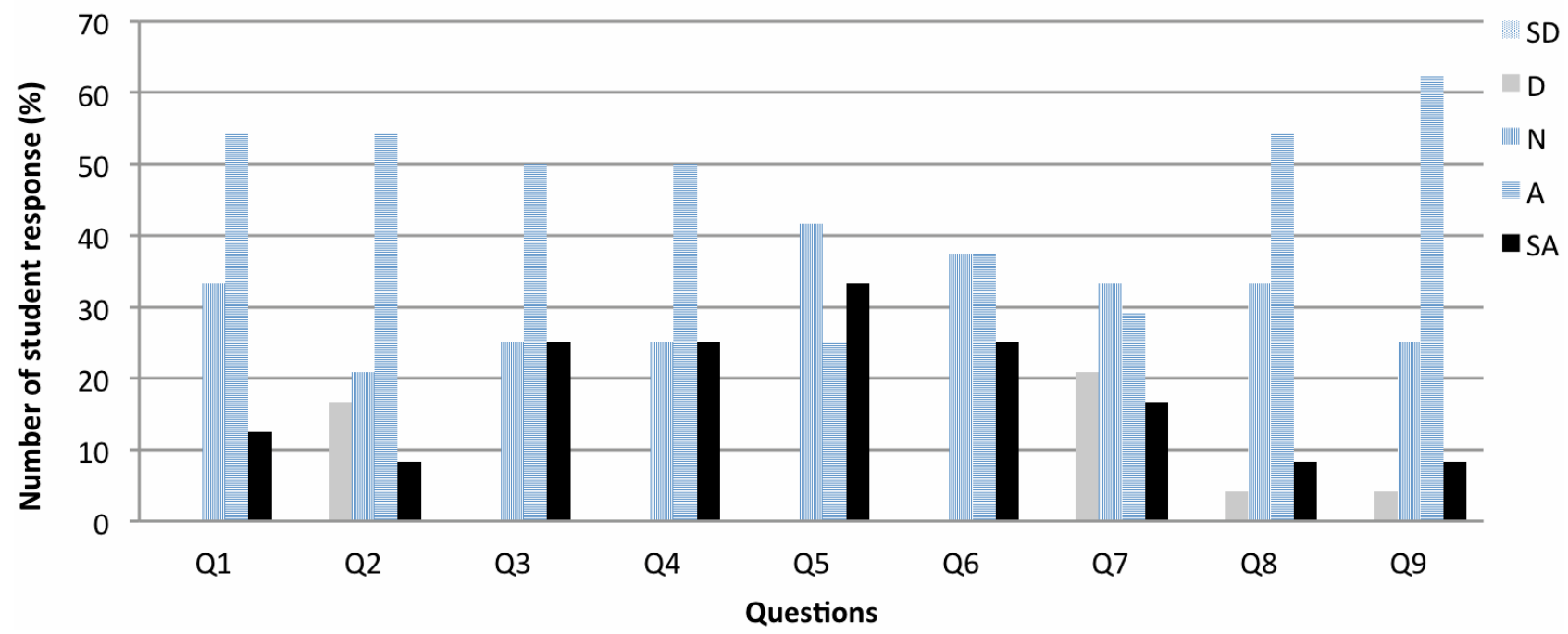

Figure 5. Students' response to the questioner on Engineering Design (ED) module. (SD: Strongly disagree, D: Disagree, N: Neither agree nor disagree, A: Agree, SA: Strongly agree). 